\title{
Long term (3 years) weight loss after low intensity endurance training targeted at the level of maximal muscular lipid oxidation
}

\author{
Edelweiss Drapier, Amira Chérif, Marlène Richou, François Bughin, Christine Fédou, Jacques Mercier, Antoine Avignon and Jean-Frédéric Brun \\ U1046 INSERM, UMR 9214 CNRS « Physiopathologie \& Médecine Expérimentale du Cœur et des Muscles - PHYMEDEXP », Unité d'Explorations
} Métaboliques (CERAMM), Université de Montpellier, Département de Physiologie Clinique, Hôpital Lapeyronie CHRU Montpellier, France

\begin{abstract}
Among various strategies of exercise intensification proposed for the management of obesity and type 2 diabetes, endurance training remains a well recognized procedure. When targeted with exercise calorimetry at levels where lipid oxidation is maximal (LIPOXmax), it has been shown to improve mitochondrial respiration, blood glucose control and blood lipids, low grade inflammation and body composition, even at low weekly volume. We investigated in this study its long term effects over 3 years $(3 \times 45 \mathrm{~min} / \mathrm{week}$ ) compared to low fat diet without exercise (LFD) and a control group without any exercise or diet (C). 88 subjects that continued LIPOXmax training more than 1 year (23 men, 65 women, age $=20-85$ years, body mass index $=23-48 \mathrm{~kg} / \mathrm{m}^{2}$ ) were compared to two matched groups (C and LFD). While $\mathrm{C}$ gained weight over this period, LFD and LIPOXmax group lose weight. Weight loss at 1 year was the same in exercise and diet group, but at 2 years and even more at 3 years there was a gradual weight regain in LFD so that results were better $(\mathrm{p}<0.01)$ in the exercise group who maintained weight loss in $80 \%$ of subjects. Average weight loss was $-2,95 \pm 0,37 \mathrm{~kg}$ after 3 months, $-4,56 \pm 0,68 \mathrm{~kg}$ after 1 year, $-5,31 \pm 1,26 \mathrm{~kg}$ at 2 years and $-8,49 \pm 2,39 \mathrm{~kg}$ at 3 years. The level at which LIPOXmax occurs is a predictor of weight loss at 1 year $(r=-0,346 \mathrm{p}<0,001)$ but not at 2 and 3 years. Weight loss at 3 months is a predictor of weight loss at 1 year $(\mathrm{r}=0,523 \mathrm{p}<0,001)$ but not at 2 and 3 years. At 1 year subjects with LIPOX $\max$ in the lower quartile $(<35 \% \mathrm{VO} 2 \mathrm{max} \mathrm{n}=23)$ lose less weight than the others $(-2.3 \pm$ 0.98 vs $-5.4 \pm 0.83 \mathrm{p}=0,05$ ) but this difference vanishes over time. This study shows that this low intensity exercise training maintains its weight-reducing effect 3 years while diet is no longer efficient, and that this effect is initially related to muscular ability to oxidize lipids but that metabolic and behavioral adaptations have been further developed and contribute to a long lasting effect.
\end{abstract}

\section{Introduction}

Whether exercise training is an important component of weightreducing strategy has been assumed for a long time [1] but strong evidence for this has been provided only quite recently [2]. High volumes of exercise are a powerful weight-reducing procedure, regardless the type of training (endurance or resistance) and its intensity [3]. However, they are too much time consuming and potentially harmful and therefore are not a realistic approach for the burden of obesity in the western countries. Surprisingly low volumes of exercise can also be quite efficient weight-reducing tools, although they induce a rather modest energy deficit [4]. This is explained by the fact that they modify in muscle cell an obesity-related metabolic program that is favorized by sedentarity. Therefore, exercise is more efficient for weight loss than can be explained by the energy deficit it induces [5].

Some sophisticated protocols involving low volumes of high intensity training are currently a matter of intensive research and give promising results [6]. However, in some individuals, it has been reported that low volumes of high intensity exercise increase appetite, apparently because they mostly promote carbohydrate oxidation, and can thus result in a decrease in blood glucose responsible for overfeeding uncompensated by calorie expenditure, which in turn results into a paradoxical weight gain [7]. Therefore, this approach with high intensity training probably requires a careful dietary control to avoid overfeeding. In addition, its efficiency over the long term is not well known.
By contrast, low intensity endurance, that promotes lipid oxidation, has been proposed since almost twenty years as a promising strategy against obesity [8-12]. When targeted with exercise calorimetry at levels where lipid oxidation is maximal (LIPOXmax), it has been shown to improve mitochondrial respiration [13], blood glucose control and blood lipids, low grade inflammation and body composition, even at low weekly volume [14]. Surprisingly, this approach generated less literature, perhaps because its weight-reducing effects over the short term, although significant, were not spectacular.

However, its prolonged use has been shown to result in a sustained weight loss [15] which contrasts with the quite constant weight regain observed in almost all classical strategies [16]. In this study we aimed at determining over 3 years the kinetics of weight evolution of patients trained with low volumes of low intensity exercise targeted by exercise calorimetry in comparison with controls who did not change their lifestyle and classical diet without exercise.

Correspondence to: Jean-Frédéric Brun, IU1046 INSERM, UMR 9214 CNRS " Physiopathologie \& Médecine Expérimentale du Cour et des Muscles PHYMEDEXP », Unité d'Explorations Métaboliques (CERAMM), Université de Montpellier, Département de Physiologie Clinique, Hôpital Lapeyronie CHRU Montpellier, France, E-mail: j-brun@chu-montpellier.fr

Key words: Exercise, lipid oxidation, calorimetry, obesity

Received: March 05, 2018; Accepted: March 21, 2018; Published: March 26 , 2018 


\section{Materials and Methods}

\section{Subjects}

We investigated in this study the weight loss over 3 years in three groups. A cohort of 88 subjects that continued LIPOXmax training more than 1 year (23 men, 65 women, age: $20-85$ years, body mass index: $23-48 \mathrm{~kg} / \mathrm{m}^{2}$ ) was compared to two matched groups: low fat diet without exercise (LFD) and a control group without any exercise or $\operatorname{diet}(\mathrm{C})$.

Low fat diet was prescribed after a personal dietary assessment by trained health professionals in order to reduced global fat intake, to add a breakfast (containing a significant amount of proteins) if it was skipped, and to suppress all fat in the evening meal. On the average this diet is close to that recommended by the American Heart Association guidelines, aiming at an energy intake of $1500 \mathrm{kcal}$ per day for women and $1800 \mathrm{kcal}$ per day for men, with $30 \%$ of calories from fat, $10 \%$ of calories from saturated fat, and an intake of $300 \mathrm{mg}$ of cholesterol per day. The participants were counseled to consume low-fat grains, vegetables, fruits, and legumes and to limit their consumption of additional fats, sweets, and high-fat snacks.

Controls were subjects that did not start any change in their diet or exercise habits despite repeated advice, but still attended regularly outpatient consultations. Patients' characteristics are shown on Table 1. The 3 cohorts were matched for weight and body mass index. However the control group is slightly younger ( 38 vs 52 and 48 years) compared to the 2 others $(\mathrm{p}=0.016)$. This difference is not likely to induce a bias in the analysis.

\section{Bioelectrical impedance measurements}

Prior to the exercise-test, subject's body composition was assessed with bioimpedance analysis with a six-terminal impedance plethismograph BIACORPUS RX 4000 Biacorpus RX4000, (SoAGIL DEVELOPPEMENT, 8 avenue Jean-Jaurès F-92130 Issy-lesMoulineaux, France) with data analysis with the software BodyComp 8.4. This device measures total resistance of the body to an alternative electric current of $50 \mathrm{kHz}$ [17-18]. Body fat mass, fat-free mass were calculated in each segment of the body according to manufacturer's database-derived disclosed equations, and total water with published equations using the classical cylindric model and Hanai's mixture theory [19].

\section{Exercise Calorimetry}

All subjects were asked to come and perform test in the morning after an overnight fast (12 hours). The test consisted of five six minute steady-state workloads theoretically set at $20,30,40,50$, and $60 \%$ of Pmax. However these intensity levels can be modified during the test according to the evolution of the respiratory exchange ratio $\left(\mathrm{RER}=\mathrm{VCO}_{2} / \mathrm{VO}_{2}\right)$ in order to obtain values of RER below and above 0.9 which is the level of the Crossover Point (COP) which is defined below. The subjects performed the test on an electromagnetically braked cycle ergometer (Ergoline Bosch 500). Heart rate and electrocardiographic parameters were monitored continuously throughout the test by standard 12-lead procedures. Metabolic and ventilatory responses were assessed using a digital computer based breath to breath exercise analyzing system (COSMED Quark CPET).

Thus, we could measure $\mathrm{VO}_{2}, \mathrm{VCO}_{2}$ (in $\mathrm{ml} / \mathrm{min}$ ) and calculate the non-protein RER. Lipid oxidation (Lipox) and carbohydrate utilization (Glucox) rates were calculated by indirect calorimetry from gas exchange measurements according to the non-protein respiratory quotient technique as previously reported [20]. This technique provided carbohydrate and lipid oxidation rates at different exercise intensities. Additionally, after smoothing the curves, we calculated the two parameters quantifying the balance between carbohydrates and lipids induced by increasing exercise intensity: the maximal lipid oxidation point (LIPOXmax) and the Crossover Point (COP). The LIPOXmax is the exercise intensity at which lipid oxidation reaches its maximal level before decreasing while carbohydrate utilization further increases. It is calculated as previously reported after smoothing of the curve plotting lipid oxidation as a function of power.

\section{Coaching and follow-up of patients}

Each subject included in the exercise group was enrolled in eight exercise sessions of $45 \mathrm{~min}$ at the LIPOXmax determined with the exercise test in order to include in his/her everyday life at least 3 similar bouts of low intensity endurance exercise per week. Subjects were followed monthly in outpatient unit for the first year and then every 3 or 4 months [21]. Only subjects who had not discontinued training after 1 year were included in this analysis and compared with the two other cohorts whose results were available in our database.

\section{Results}

There were 327 patients included in the LIPOXmax group, compared to 183 in the low fat group and 63 in the control group. We only considered in this study patients following the program after 1 year. There were respectively 88 at one year, 37 at 2 years and 8 at three years. In comparison in the low fat group there were 183 subjects at the beginning, 48, 9 and 8. Controls were 63, 16, 7 and 5.

Therefore at 1 year the percentage of drop-out was the same (respectively of $-73 \%,-74 \%$ and $-75 \%$ ). If we consider only subjects that continued more than 1 year, among them, at 2 years there were respectively $-58 \%,-81 \%$ and $-56 \%$ drop-outs. At 3 years there were respectively $-91 \%-83 \%$ and $-69 \%$ drop-outs. However, since the study is still in progress, these rates of drop out do not mean that all these subjects discontinue the weight reducing procedure, as commented in the discussion.

Figure 1 shows the average evolution of body weight over 3 years. While $\mathrm{C}$ gained weight over this period, LFD and LIPOXmax group lose weight. Weight loss at 1 year was the same in exercise and diet group, but at 2 years and even more at 3 years there was a weight regain in LFD so that results were better $(\mathrm{p}<0.01)$ in the exercise group who maintained weight loss in $80 \%$ of subjects. Average weight loss was $-2,95 \pm 0,37 \mathrm{~kg}$ after 3 months, $-4,56 \pm 0,68 \mathrm{~kg}$ after 1 year, $-5,31 \pm 1,26$ $\mathrm{kg}$ at 2 years and $-8,49 \pm 2,39 \mathrm{~kg}$ at 3 years.

Table 1. Study subjects (mean \pm SEM). Comparison: **LIPOXmax and LFD groups are matched for age, weight and body mass index, but the control group is slightly younger compared to the 2 others $(\mathrm{p}=0.016)$.

\begin{tabular}{|c|c|c|c|c|}
\hline & Gender (F/M) & AGE (yr) & Weight (kg) & Height (m) \\
\hline CONTROLS $(n=5)$ & $4 F / 1 M$ & $38.29 \pm 4.07 * *$ & $102.90 \pm 11.05$ & $1.68 \pm 0.05$ \\
\hline LIPOXmax $(n=88)$ & $65 F / 23 M$ & $51.66 \pm 1.50$ & $93.43 \pm 2.18$ & $1.66 \pm 0.01$ \\
\hline LOW FAT $(n=34)$ & $21 \mathrm{~F} / 7 \mathrm{M}$ & $48.00 \pm 2.41$ & $93.48 \pm 4.48$ & $33.74 \pm 2.50$ \\
\hline
\end{tabular}




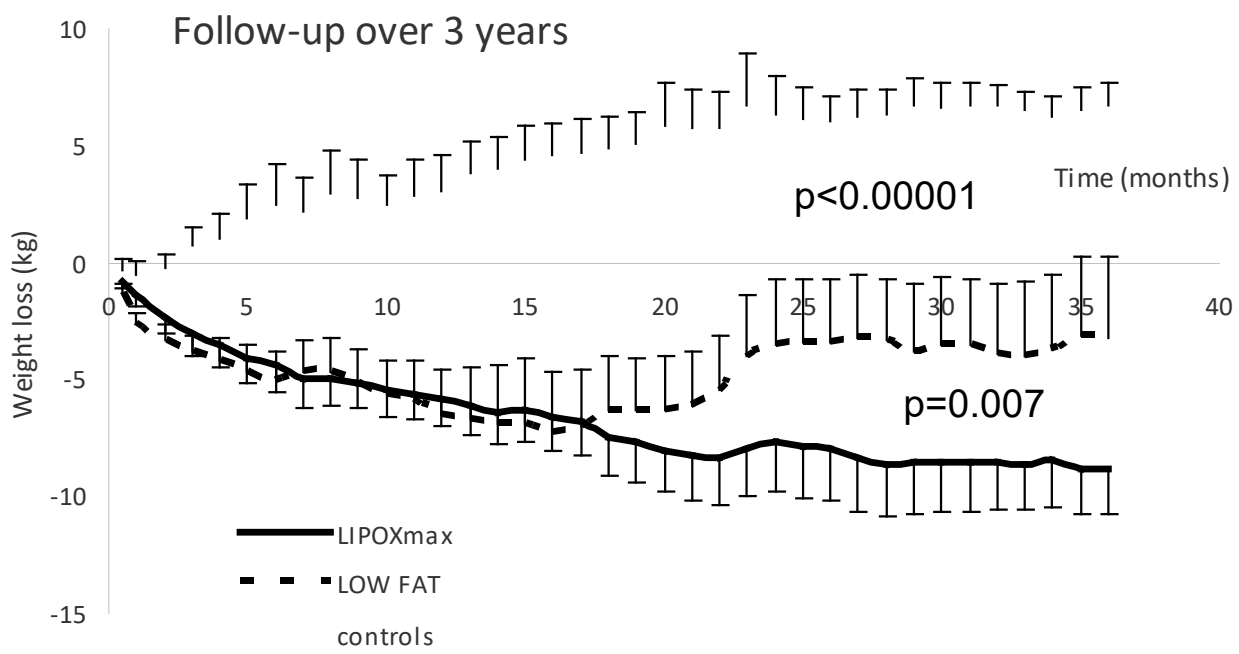

Figure 1. respective evolution of weigh (in $\mathrm{kg}$ ) over the 3 years. It can be seen that C gained weight over this period, while LFD and LIPOXmax group lose weight. Weight loss at 1 year was the same in exercise and diet group, but at 2 years and even more at 3 years there was a weight regain in LFD so that results were better ( $<<0.01$ ) in the exercise group who maintained weight loss in $80 \%$ of subjects. Average weight loss was $-2,95 \pm 0,37 \mathrm{~kg}$ after 3 months, $-4,56 \pm 0,68 \mathrm{~kg}$ after 1 year, $-5,31 \pm 1,26 \mathrm{~kg}$ at 2 years and $-8,49 \pm 2,39 \mathrm{~kg}$ at 3 years.

Figure 2 shows the individual responses to the exercise strategy at 1 year. It can be seen that there are $82 \%$ responders (among whom $25 \%$ are good responders losing more than $10 \%$ of the initial weight), and $18 \%$ non responders. As shown on Figure 3, weight loss at 3 months is a predictor of weight loss at 1 year $(r=0,523 \mathrm{p}<0,001)$ but not at 2 and 3 years. The level at which LIPOXmax occurs is a predictor of weight loss at 1 year $(r=-0,346 p<0,001)$ but not at 2 and 3 years. Weight loss at 3 months is a predictor of weight loss at 1 year $(r=0,523 \mathrm{p}<0,001)$ but not at 2 and 3 years. As shown on Figure 4, at 1-year subjects with LIPOX max in the lower quartile $(<35 \% \mathrm{VO} 2 \max n=23)$ lose less weight than the others $(-2,3 \pm 0,98$ vs $-5,4 \pm 0,83 \mathrm{p}=0,05)$ but this difference vanishes over time.

\section{Discussion}

This study evidences for the first time that low intensity exercise training targeted at the LIPOXmax maintains its weight-reducing effect 3 years, while diet, used as a comparator, is no longer efficient. In addition, we show that this effect is initially related to muscular ability to oxidize lipids. In the subset of subjects who are already "good fat oxidizers "at the onset of the study, better results of weight loss are evidenced.

The main limit of this study is obviously that this is an observational study, without initial randomization. However the cohort of LIPOXmax trained subjects is compared to two control groups. The groups LIPOXmax and LFD are matched for BMI and age, but the control group is slightly younger $(\mathrm{p}=0.016)$ than the two others. This modest difference in age is not likely to induce a bias, since it is not likely that younger people are prone to a lower weight loss. The opposite should rather be expected. Therefore, our groups are probably well matched for possible confounding factors.

The design of the study makes that only patients that were still followed are included in the analysis, which is thus not performed in "intention to treat". One can assume that a significant proportion of subjects that discontinued the procedure are people who were deceived by its efficacy and thus were poor responders, so that a study in intention to treat would yield on the average a lower weight loss. The strength of this study is to show a sample of subjects in conditions of 'true life', continuing their training over 3 years or more with on

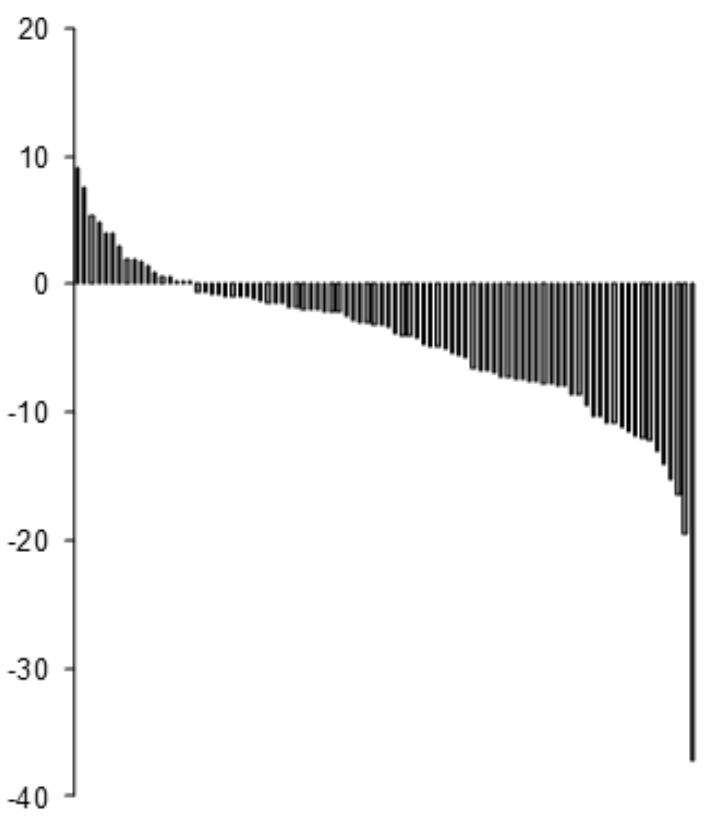

Figure 2. Individual weight loss responses in the LIPOXmax group. There are $82 \%$ responders (among whom $25 \%$ are good responders losing more than $10 \%$ of the initial weight), and $18 \%$ non responders who lose no weight or even gain weight.

the average persisting weight-reducing effects. A randomized control trial of three similar groups will be useful to do, but such a study will probably be extremely expensive and difficult to manage.

Our low fat diet group is a cohort of obese subjects routinely treated by diet only in our unit. As explained above, this low-fat, restricted-calorie diet closely fits with the guidelines of the American Heart Association [22]. The weight-reducing effect of this procedure at 24 months $(-5.38 \pm 2.29)$ is close to that reported for low fat diet in the controlled trial of Shai [23] (3.3 kg, grossly $4 \%$ ).

The control group is not a series of patients randomized and assigned to a non-treatment follow up, but a sample of subjects that still wanted to be followed but were unable to start a weight reducing procedure, expecting to do so in a next future. The evolution of weight 


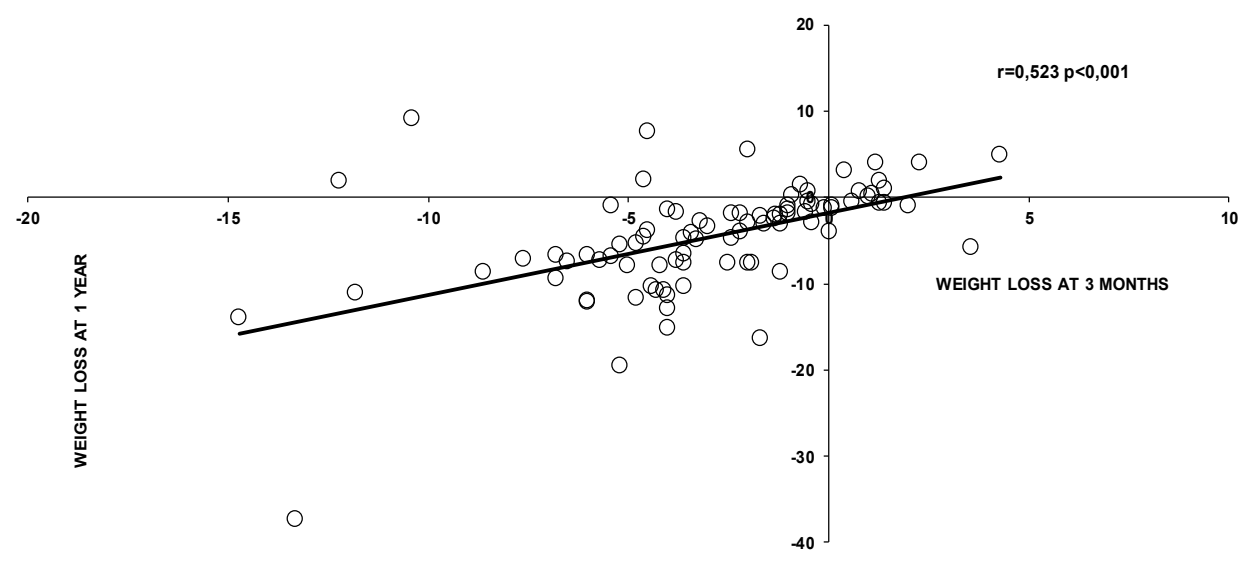

Figure 3. Correlation between weight loss at 3 months and weight loss at 1 year.

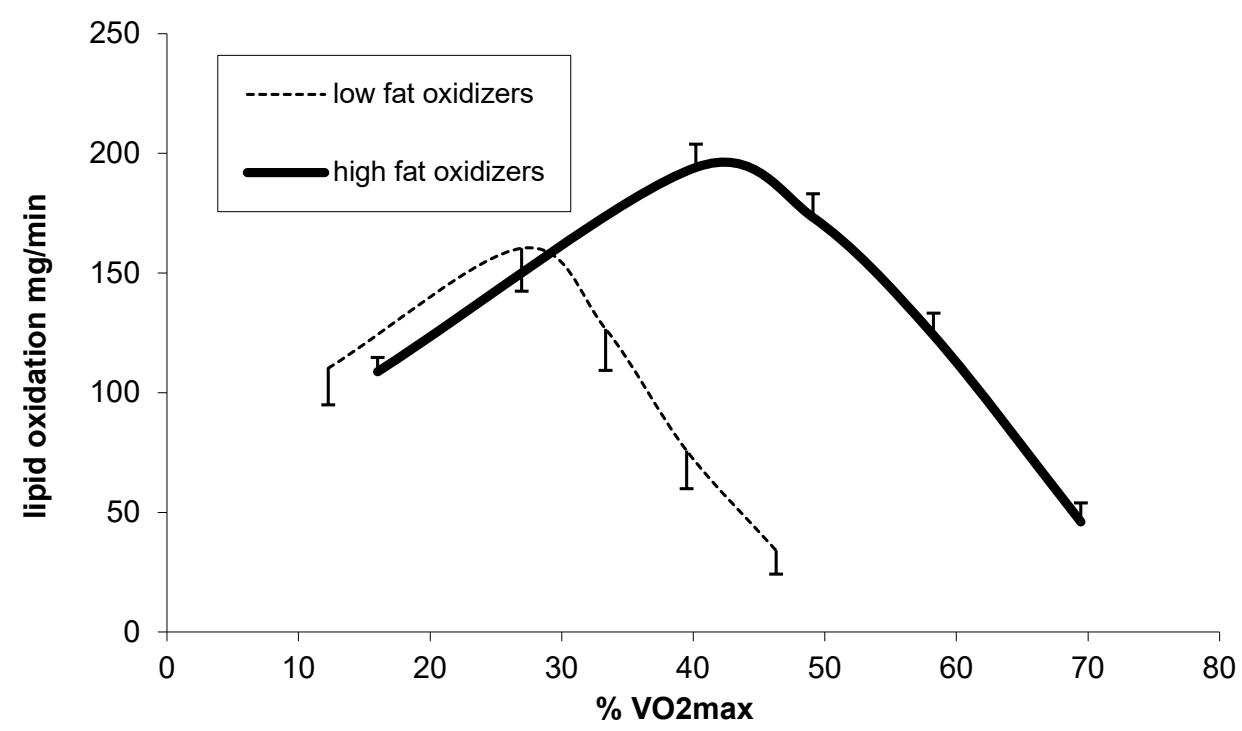

Figure 4. Comparison of the lipid oxidation curve among good fat oxidizers (the 3 highest quartiles of LIPOXmax) and the lower quartile.

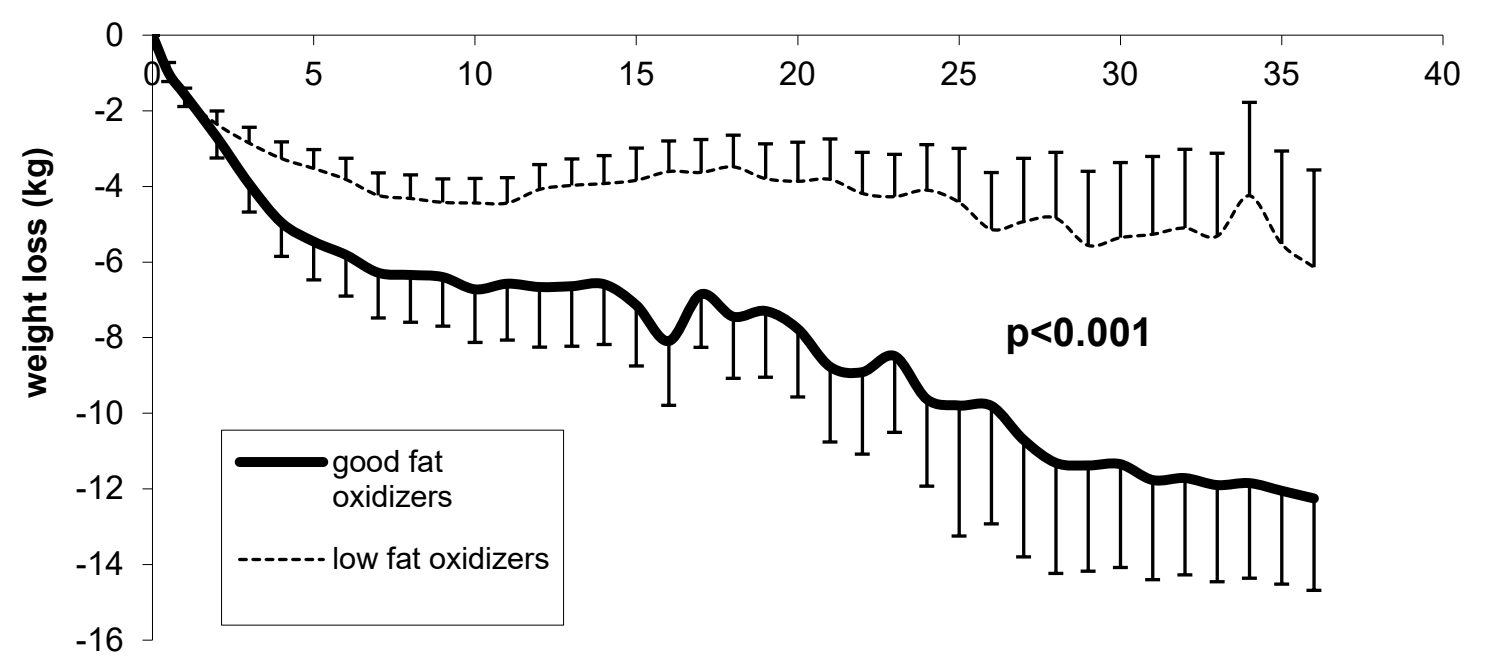

time (months)

Figure 5. Comparison of weight loss among good fat oxidizers (the 3 highest quartiles of LIPOXmax) and the lower quartile (low fat oxidizers) defined according to the initial exercise calorimetry. 
in this control group is similar to that reported in STRRIDE [24], which is $+1.0 \pm 2.7 \%$ of initial body weight. In our series it is at 8 months $1.85 \pm 0.61 \%$. Interestingly, in this group weight gain increases after time: $4.07 \pm 1.17 \%$ at 24 months, and $6.82 \pm 1.31 \%$ at 36 months. This finding clearly shows that continued physical inactivity results in progressive weight gain, as pointed out by the authors of STRRIDE [24].

Another concern is the issue of attrition. Obviously, there is a significant number of patients that were lost of view during this period. Over the first year subjects enrolled in the two programs (LIPOXmax or LFD) had the same number of drop outs, e.g. almost 75\%, which was also the number of control patients (adhering to none of the programs) that were lost of view. In obesity trials, attrition rates can be evaluated on the average at $50 \%$ [25]. Actually a wide range of percentages (from 10 to $80 \%$ ) can be found in the literature [26]. Clearly, attrition should be considered as a major cause of treatment failure in the field of obesity. In the abovementioned DIRECT study [23], the reported attrition rate is much lower, since adherence to diet was $95.4 \%$ at 1 year and $84.6 \%$ at 2 years, but the conditions of this important trial are not those of usual obesity managing, and the follow-up of subjects is much closer.

In our study which represents conditions of usual obesity follow up in our unit, the attrition rate at the beginning is rather high, but is not significantly higher than in other studies on obesity [27]. Obviously, such an elevated number of drop outs may represent a bias. Some of these patients have perhaps stopped this protocol because they found they did not lose enough weight. However, it is known that the percentage of drop out is far to represent a percentage of failures. Over a 36-month follow-up, it has been reported by Dalle Grave [28] that most of the drop outs were actually people confident in their ability to lose additional weight without professional help, and that achieved a mean weight loss that was on average larger than in continuers. Therefore, it is clear that not all the dropouts are treatment failures [28], so that the average weight loss measured in continuers is not an overestimation of the overall result.

On the whole, whatever its methodological limits due to the lack of randomization, this study unequivocally demonstrates that many patients included in such a protocol lose weight for at least 3 years, and therefore that LIPOXmax training is efficient for losing weight on the long term in a significant percentage of obese subjects. A more indepth analysis of these results shows that the weight-lowering effect is initially related to muscular ability to oxidize lipids. This relationship is logic. Lipid oxidation during exercise is a reflect of the percentage of type 1 (oxidative) muscle fibers [29] and correlated to lipid oxidation over $24 \mathrm{hr}$, indicating that lipid oxidizers during exercise are also lipid oxidizers at rest [30]. In addition, an exercise bout of low intensity exercise performed at fast in the morning increases the oxidative use of lipids all over the day [31]. Exercise targeted on lipids also corrects obesogenic disturbances such as insulin resistance [32].

Actually, this relationship between lipid oxidation at the beginning of the study and weight loss is no longer found after 1 year. This may indicate that metabolic and behavioral adaptations have been further developed and contribute to a long-lasting effect, regardless the initial profile of balance of substrates. As proposed by Houmard [33] exercise programs further muscle metabolism in obese subjects and is thus efficient as a metabolism programmer even at low intensity, and even if it elicits a moderate calorie expenditure [34]. This effect is due to a mitochondrial remodeling in human skeletal muscle [35].

The average profile of weight loss in the exercise group displays an unusual shape which requires some comments. In almost all studies there is a tendency to weight regain over time, which is due to many endocrine, metabolic and behavioral alterations. On the average weight loss induces a host of powerful homeostatic mechanisms aiming at preserving or even increasing body fat stores [36]. In obese persons who have lost weight, multiple compensatory mechanisms encouraging weight gain have been evidenced to persist for at least 1 year. More precisely, there is a decrease in hormones which reduce the drive to eat (leptin, Peptide YY, Amylin, cholecystokinin) and an increase in the orexigenic hormone ghrelin associated with a rise in appetite as well as increased fasting and postprandial ratings of hunger and desire to eat [37].

Interestingly, exercise may modify eating behavior, either by a satietogenic effect or by an increase in orexigenic drive [38]. We have previously shown that exercise targeted at the LIPOXmax is satietogenic and decreases nibbling and calorie intake [39], in contrast with exercise targeted at higher intensities where carbohydrate oxidation predominates, which are orexigenic and may frequently target weight gain [40]. It is likely that when exercise is prescribed at low volumes (180-240 $\mathrm{min} /$ week) most of its effects are actually due to these effects on eating behavior, since the caloric deficit they induce is very low and cannot by itself explain weight loss.

This interesting (and unexpected) long lasting profile of weight loss observed in the current study can be explained by several mechanisms. First of all, this strategy rather induces muscle metabolism (and eating behavior) re-programming than energy deficit [5]. On the other hand, patients are in situation of true life and are no longer submitted to a constraint, which would include a risk of relapse when the constraint weakens, as has been shown in several studies. For example in the KAROLA study, patients assigned to regular exercise for the treatment of coronary heart disease maintain a regular activity level when it is prescribed at 2-4 times a week, while higher activity rates are usually not maintained over the 10 years follow-up period [41].

In addition, the Weight Loss Maintenance Randomized Controlled Trial has shown that over the long term regular follow up of patients results in a higher weight loss than telemedicine alone and even more simple advice with no follow-up [42]. We think that the shape of prolonged efficacy of the weight loss curve is due to both the "reprogramming" effect of LIPOXmax training on mitochondrial function [13,29,35] and eating behavior [39] and this design with regular follow up in outpatient unit and a reasonable number of weekly exercise sessions that prevents training discontinuation over the long term.

In conclusion, our study clearly demonstrates that at least a subset of patients included in the LIPOXmax procedure are still losing weight at 3 years. Such a long-term effect is not usual in obesity studies and will require to be further studied. The next step of this study is to investigate whether this weight loss persists at 4 years or if there is a later tendency to weight regain as observed with almost all other slimming procedures.

\section{References}

1. Tremblay A, Després JP, Leblanc C, Craig CL, Ferris B, et al. (1990) Effect of intensity of physical activity on body fatness and fat distribution. Am J Clin Nutr 51: 153-157. [Crossref]

2. Baillot A, Romain AJ, Boisvert-Vigneault K, Audet M, Baillargeon JP, et al. (2015) Effects of Lifestyle Interventions That Include a Physical Activity Component in Class II and III Obese Individuals: A Systematic Review and Meta-Analysis. PLoS One 10: e0119017. [Crossref]

3. Dutheil F, Lac G, Lesourd B, Chapier R, Walther G, et al. (2013) Different modalities of exercise to reduce visceral fat mass and cardiovascular risk in metabolic syndrome: the RESOLVE randomized trial. Int J Cardiol 168: 3634-3642. [Crossref] 
4. Johnson J, Slentz C, Houmard JA, Samsa GP, Duscha BD, et al. (2007) Exercise training amount and intensity effects on metabolic syndrome: STRRIDE. Am J Cardiol 100:1759-1767. [Crossref]

5. Brun JF (2015) Exercise Makes More than an Energy Deficit: Toward Improved Protocols for the Management of Obesity? EBioMedicine 18: 1862-1863. [Crossref]

6. Gillen JB, Gibala MJ (2014) Is high-intensity interval training a time-efficient exercise strategy to improve health and fitness? Appl Physiol Nutr Metab 39: 409-412. [Crossref]

7. Brun JF, Romain AJ, Sferlazza A, Fédou C, Raynaud de Mauverger E, et al. (2016) Which individuals become fatter when they practice exercise? Sci Sports 31: 214218 .

8. Perez-Martin A, Mercier J (2001) Stress tests and exercise training program for diabetics - Initial metabolic evaluation. Ann Endocrinol 62: 291-293.

9. Dériaz O, Dumont M, Bergeron N, Després JP, Brochu M, et al. (2001) Skeletal muscle low attenuation area and maximal fat oxidation rate during submaximal exercise in male obese individuals. Int J Obes Relat Metab Disord 25: 1579-1584. [Crossref]

10. Pérez-Martin A, Dumortier M, Raynaud E, Brun JF, Fédou C, et al. (2001) Balance of substrate oxidation during submaximal exercise in lean and obese people. Diabetes Metab 27: 466-474. [Crossref]

11. Achten J, Gleeson M, Jeukendrup AE (2002) Determination of the exercise intensity that elicits maximal fat oxidation. Med Sci Sports Exerc 34: 92-97. [Crossref]

12. Achten J, Jeukendrup AE (2004) Optimizing fat oxidation through exercise and diet. Nutrition 20: 716-727. [Crossref]

13. Brandou F, Dumortier M, Garandeau P, Mercier J, Brun JF (2003) Effects of a two-months rehabilitation program on substrate utilization during exercise in obese adolescents. Diabetes Metab 29: 20-27. [Crossref]

14. Venables MC, Jeukendrup AE (2008) Endurance training and obesity: effect on substrate metabolism and insulin sensitivity. Med Sci Sports Exerc 40: 495-502. [Crossref]

15. Bordenave S, Metz L, Flavier S, Lambert K, Ghanassia E, et al. (2008) Training-induced improvement in lipid oxidation in type 2 diabetes mellitus is related to alterations in muscle mitochondrial activity. Effect of endurance training in type 2 diabetes. Diabetes Metab 34: 162-168. [Crossref]

16. Besnier F, Lenclume V, Gérardin P, Fianu A, Martinez J, et al. (2015) Individualized exercise training at maximal fat oxidation combined with fruit and vegetable-rich diet in overweight or obese women: The LIPOXmax-Réunion randomized controlled trial. PLoS One 10: e0139246. [Crossref]

17. Guiraudou M, Fédou C, Romain AJ, Sferlazza A, Calas E, et al. (2015) Effects over one year of low-intensity endurance exercise targeted at the level of maximal lipid oxidation. Sci Sports 30: e127-e131.

18. Svetkey LP, Stevens VJ, Brantley PJ, Appel LJ, Hollis JF, et al. (2008) Comparison of Strategies for Sustaining Weight Loss: The Weight Loss Maintenance Randomized Controlled Trial. JAMA 299: 1139-1148. [Crossref]

19. Brun JF, Guiraudou M, Mardemootoo C, Traoré A, Raingeard I, et al. (2013) Validation de la mesure segmentaire de la composition corporelle en comparaison avec la DEXA: intérêt de la mesure de la masse grasse tronculaire. Sci Sports 28: 158-162.

20. Guiraudou M, Maimoun L, Dumas J-M, Julia M, Raingeard I, et al. (2015) Composition corporelle mesurée par impédancemétrie segmentaire (BIAS) et performance de sprint chez les rugbymen / Body composition measured by bioimpedance segmental (BIAS) analysis and sprint performance in rugby players. Sci Sports 30: 298-302.

21. Jaffrin MY, Morel H (2008) Body fluid volumes measurements by impedance: A review of bioimpedance spectroscopy (BIS) and bioimpedance analysis (BIA) methods. Med Eng Phys 30: 1257-1269 [Crossref]

22. Brun JF, Varlet-Marie E, Romain AJ, Mercier J (2011) Measurement and physiologica relevance of the maximal lipid oxidation rate during exercise (LIPOXmax). INTECH book. "Sports Medicine and Sports Injuries.

23. Brun JF, Malatesta D, Sartorio A (2012) Maximal lipid oxidation during exercise: A target for individualizing endurance training in obesity and diabetes? J Endocrino Invest 35: 686-691. [Crossref]

24. Krauss RM, Eckel RH, Howard B, Appel LJ, Daniels SR, et al. (2000) AHA Dietary Guidelines: revision 2000: a statement for healthcare professionals from the Nutrition Committee of the American Heart Association. Circulation 102: 2284-2299. [Crossref]

25. Shai I, Schwarzfuchs D, Henkin Y, Shahar DR, Witkow S, et al. (2008) Weight loss with a low-carbohydrate, Mediterranean, or low-fat diet. $N$ Engl J Med 359: 229-241. [Crossref]
26. Slentz CA, Aiken LB, Houmard JA, Bales CW, Johnson JL, et al. (2005) Inactivity, exercise, and visceral fat. STRRIDE: a randomized, controlled study of exercise intensity and amount. J Appl Physiol (1985) 99: 1613-1618. [Crossref]

27. Fidelix YL, Farias Júnior JC, Lofrano-Prado MC, Guerra RL, Cardel M, et al. (2015) Multidisciplinary intervention in obese adolescents: predictors of dropout. Einstein (Sao Paulo) 13: 388-394. [Crossref]

28. Moroshko I, Brennan L, O'Brien P (2011) Predictors of dropout in weight loss interventions: a systematic review of the literature. Obes Rev 12: 912-934. [Crossref]

29. Batterham M, Tapsell LC, Charlton KE (2016) Predicting dropout in dietary weight loss trials using demographic and early weight change characteristics: Implications for trial design. Obes Res Clin Pract 10: 189-196. [Crossref]

30. Dalle Grave R, Melchionda N, Calugi S, Centis E, Tufano A, et al. (2005) Continuous care in the treatment of obesity. An observational multicentre study. J Intren Med 258: 265-273. [Crossref]

31. Sahlin K, Mogensen M, Bagger M, Fernström M, Pedersen PK (2007) The potential for mitochondrial fat oxidation in human skeletal muscle influences whole body fat oxidation during low-intensity exercise. Am J Physiol Endocrinol Metab 292: E223230. [Crossref]

32. Robinson SL, Hattersley J, Frost GS, Chambers ES, Wallis GA (2015) Maximal fat oxidation during exercise is positively associated with 24-hour fat oxidation and insulin sensitivity in young, healthy men. J Appl Physiol 1985 118: 1415-1422. [Crossref]

33. Iwayama K, Kurihara R, Nabekura Y, Kawabuchi R, Park I, et al. (2015) Exercise increases $24-\mathrm{h}$ fat oxidation only when it is performed before breakfast. EBioMedicine 2: 2003-2009. [Crossref]

34. Dumortier M, Brandou F, Perez-Martin A, Fedou C, Mercier J, et al. (2003) Low intensity endurance exercise targeted for lipid oxidation improves body composition and insulin sensitivity in patients with the metabolic syndrome. Diabetes Metab 29: 509-518. [Crossref]

35. Houmard JA, Pories WJ, Dohm GL (2012) Severe obesity: evidence for a deranged metabolic program in skeletal muscle? Exerc Sport Sci Rev 40: 204-210. [Crossref]

36. Powers SK (2017) Exercise: Teaching myocytes new tricks. J Appl Physiol (1985) 123 460-472. [Crossref]

37. Huffman KM, Koves TR, Hubal MJ, Abouassi H, Beri N, et al. (2014) Metabolite signatures of exercise training in human skeletal muscle relate to mitochondria remodelling and cardiometabolic fitness. Diabetologia 57: 2282-2295. [Crossref]

38. Evert AB, Franz MJ (2017) Why Weight Loss Maintenance Is Difficult. Diabetes Spectr 30: 153-156. [Crossref]

39. Sumithran P, Prendergast LA, Delbridge E, Purcell K, Shulkes A, et al. (2011) Longterm persistence of hormonal adaptations to weight loss. N Engl J Med 365: 1597-1604. [Crossref]

40. King N, Caudwell NP, Hopkins M, Stubbs JR, Naslund E, et al. (2009) Dual-process action of exercise on appetite control: increase in orexigenic drive but improvement in meal-induced satiety. Am J Clin Nutr 90: 921-927. [Crossref]

41. Guiraudou M, Romain AJ, Mawunu M, Bedjih K, Fédou C, et al. (2016) Effet chroniques de l'exercice ciblé au niveau d'oxydation maximale des lipides (LIPOXmax) sur le comportement alimentaire de sujets obèses sédentaires. Sci Sports 31: 13-18.

42. Brun JF, Romain AJ, Sferlazza A, Fédou C, Raynaud de Mauverger E, et al. (2016) Which individuals become fatter when they practice exercise? Sci Sports 31: 214-218

43. Mons U, Hahmann H, Brenner H (2014) A reverse J-shaped association of leisure time physical activity with prognosis in patients with stable coronary heart disease: evidence from a large cohort with repeated measurements. Heart 100: 1043-1049. [Crossref]

44. Svetkey LP, Stevens VJ, Brantley PJ, Appel LJ, Hollis JF, et al. (2008) Comparison of strategies for sustaining weight loss: the weight loss maintenance randomized controlled trial. JAMA 299: 1139-1148. [Crossref]

Copyright: (C2018 Drapier E. This is an open-access article distributed under the terms of the Creative Commons Attribution License, which permits unrestricted use, distribution, and reproduction in any medium, provided the original author and source are credited. 